\title{
Complexidade social, sistemas comunicativos e gênese da escrita cuneiforme ${ }^{1}$
}

\author{
MARCELO REDE \\ Universidade Federal Fluminense
}

\begin{abstract}
RESUMO: Este estudo expõe e discute as teorias mais recentes sobre a gênese da escrita na antiga Mesopotâmia, em particular sob a ótica da articulação entre a gênese do sistema cuneiforme e a diversidade e função dos sistemas comunicativos, no quadro de complexidade social crescente do final do período Neolítico.
\end{abstract}

PALAVRAS-CHAVE: cuneiforme; escritura; Mesopotâmia; sistemas de comunicação; complexidade social.

Os sistemas de comunicação, como qualquer outro fenômeno social, são enraizados em seu contexto histórico. Isso não significa dizer que sejam, simplesmente, o resultado de uma série de conjunções, aleatórias ou não, entre processos que lhes são externos e anteriores. Também não significa o contrário: que constituam, por si mesmos, o único ou principal fator causal dos processos sociais, econômicos e, sobretudo no caso, culturais que compõem a realidade humana. A boa resposta parece, antes, situar-se em uma zona muito mais complexa e fluida de interações entre campos distintos, mas nunca totalmente autônomos, os quais poderíamos distinguir com alguma legitimidade apenas para fins de compreensão. A compartimentação está mais no nível da especulação historiográfica do que da realidade histórica.

No entanto, seremos incapazes de estabelecer relações? Estaremos impedidos, face à monstruosa complexidade de nossos objetos de estudo, de supor causalidades, hierarquias de importância ou mesmo de impor uma ordem cronológica aos eventos?

A questão da gênese e desenvolvimento da escrita cuneiforme parece um excelente campo de provas, com todos os riscos comportados pelos testes das hipóteses. A começar pelas próprias noções de origem e desenvolvimento. Cada qual foi alvo de extensos debates no campo das ciências humanas, sem que se pudesse ter chegado a uma adesão irrestrita ou a um descarte definitivo. Se a idéia de origem esteve muitas vezes acompanhada de uma indesejável carga criacionista ou mesmo aliada à idéia de uma invenção ex-nihilo, contribuindo assim para extirpar o aparecimento da escrita do quadro que lhe atribuía sentido, nada em sua crítica pode menosprezar o fato de que o fenômeno sempre foi circunscrito no tempo e no espaço, marcando um antes e um depois na história dos sistemas de comunicação e das sociedades humanas. Por outro lado, o evolucionismo subjacente à noção de desenvolvimento não pode ser sumariamente recusado, apesar de suas consequiências deletérias (penso 
especialmente no etnocentrismo ou na suposição da existência de superioridades raciais), sem que se ampute o raciocínio de um importante instrumento de explicação que lhe permite estabelecer a tipificação e a comparação entre momentos, lugares e mesmo culturas distintas.

O problema que se coloca, portanto, é o de explicar a gênese e a trajetória de um sistema de escrita particular, situando-o em seu contexto histórico, sem renunciar à proposição das articulações necessárias ao seu entendimento, mas, ao mesmo tempo, procurando evitar as armadilhas do simplismo e do mecanicismo. Uma farta literatura buscou estabelecer as conexões entre o sistema cuneiforme e a emergência da economia agro-pastoril, a centralização do poder, as novas formas de manifestação religiosa, ou mesmo as transformações da mentalidade coletiva. Os resultados foram variáveis e, em todo caso, a considerável renovação do campo, nos últimos anos, justifica uma apreciação do problema.

O hábito, bem enraizado na tradição, de considerar o surgimento da escrita como o divisor de águas entre a pré-história e a história propriamente dita não deixa de estar relacionado a uma visão particular do fenômeno, além de revelar muito sobre a importância do documento escrito para a historiografia. A tendência que conferiu à escrita uma natureza matricial marcou profundamente a pesquisa e manifestou-se de formas variadas. Contentemo-nos apenas em enfatizar estes dois aspectos: de um lado, as diversas tentativas de definição do conceito de "civilização", em que a Mesopotâmia se enquadra de modo inaugural, sempre implicaram algum tipo de oposição entre sociedades letradas e sociedades de tradição oral; de outro, as condições de nascimento da assiriologia, inaugurada a partir de um esforço de deciframento de escrituras e línguas mortas por milênios, conferiram-lhe indelevelmente seu caráter de saber sobre escritos, mais do que sobre sociedades.

Seria inexato pensar, no entanto, que a defesa de um florescimento mais ou menos repentino do grafismo ou de seus atributos sociais distintivos seja um sintoma dos preconceitos ou das fragilidades documentais próprias da infância do estudo. Veremos adiante que muitos dos melhores especialistas da atualidade enfatizam pontos semelhantes, ainda que dentro de um quadro de referências totalmente diverso e a partir de uma base informacional impensável há cem, ou mesmo trinta anos atrás.

Foi somente a partir da década de setenta que o debate sobre as relações entre a origem da escrita cuneiforme e o incremento da complexidade social no decorrer do período neolítico ganhou o atual estatuto, embora a especulação não estivesse ausente das reflexões dos historiadores e arqueólogos até então. Bastaria lembrar as sínteses clássicas de V. Gordon Childe para mostrar o contrário. A nova abordagem foi o resultado, em parte, do aparecimento de dados arqueológicos inéditos, em parte, da percepção de que materiais há muito conhecidos e tidos como independentes poderiam estar relacionados, em seu contexto social de origem, de modo até então insuspeito. É preciso dizer, porém, que dois foram os passos decisivos: em primeiro lugar, uma inovação metodológica no tratamento das fontes, que alterou substancialmente a operação analítica que leva do artefato arqueológico ao objeto em seu quadro de vida e que implicou uma dessacralização do papel do documento escrito face aos demais elementos da cultura material. Em segundo lugar, uma guinada teórica que reintegrou o registro gráfico no contexto das transformações profundas por que passavam as sociedades próximo-orientais nos milênios que viram a alteração de toda sua base de existência material, com a domesticação dos animais e a agricultura, e a passagem a um modo de vida sedentário e urbano, centrado nas organizações complexas dos templos e palácios, com todos os ingredientes de ordem cognitiva implicados pelo processo. 


\section{Gênese da escrita: debates e tendências}

Coube a Denise Schmandt-Besserat sistematizar essa nova visão e tirar dela as conseqüências para uma reinterpretação do fenômeno da escrita. Seu exaustivo trabalho procurou mostrar as relações entre os vários sistemas de registro e comunicação utilizados desde pelo menos o $9^{\circ}$ milênio a.C. e o aparecimento do cuneiforme. A importância e o impacto de suas idéias exigem uma exposição detalhada de alguns pontos.

No centro de sua teoria, encontramos um postulado geral que advogou não apenas uma sucessão de sistemas de registro e controle, como também uma derivação de ordem genética entre eles. Mas, sobretudo, um postulado que se pretendia fortemente ancorado nas evidências arqueológicas, nos resíduos materiais de tais sistemas. De fato, desde a década de trinta, as publicações e os relatórios das escavações revelavam a existência de pequenos objetos medindo entre 1 e $3 \mathrm{~cm}$., feitos de argila ou, mais raramente, de pedra (que ficarão conhecidos como tokens) apresentando formas variadas, quer geométricas (esferas, cilindros, discos achatados, cones, tetraedros etc.) quer "naturalísticas" (jarros, cabeças de animais, pão etc.), alguns deles, mais recentes, cotendo incisões ou furos que permitiam sua articulação. No sítio de Uruk (que, justamente, terá um papel ímpar no aparecimento da escrita cuneiforme), foram encontrados primeiramente nos níveis estratigráficos correspondentes ao fim do período de Uruk, entre 3200-3000 a.C. Julius Jordan, que publicou uma série deles em 1931 (Jordan, 1931, p. 47s., fig.41), considerou-os imitações de "objetos da vida cotidiana" (Gegenstände des täglichen Lebens), ligados à esfera religiosa (no que contribuiu o local de achado, o complexo templário de Eanna). Por volta da mesma época, na acrópole de Susa, eram encontrados objetos semelhantes, sendo que alguns estavam encapsulados em esferas confeccionadas em argila (o que se verificaria, mais tarde, também em Uruk ${ }^{2}$ ). Tais recipientes, conhecidos como bullae, variavam, em geral, entre 5 e $10 \mathrm{~cm}$. de diâmetro. R. de Mecquenem, responsável pela missão de Susa, sugeriu que os minúsculos artefatos fossem "des images pour aider l'enfant à apprendre des mots" 3 (Mecquenem, 1943, p. 27; cf. também 1934, p.193, em que o arqueólogo atribuía uma função lúdica aos seus achados: "pions de jeu"). Também Louis Le Breton (Breton, 1957, p. 112) viu-os simplesmente como "gamepieces". Referindo-se aos equivalentes de Uruk, H. J. Lenzen (Lenzen, 1965, p. 32) falou de "amuletos" (Amulette) e "esferas" (Kugeln), mas sem avançar em uma interpretação de caráter religioso.

Duas referências são importantes para compreender a interpretação inovadora desses conjuntos artefactuais por Schmandt-Besserat. Em 1959, A. Leo Oppenheim, avaliando o material proveniente das escavações de Nuzi, propôs a existência de um duplo mecanismo contábil operado pelo palácio local em meados do segundo milênio a.C.: o controle escrito tradicional, em tabletes e utilizando o sistema cuneiforme, e um dispositivo baseado na manipulação de recipientes de argila ocos ("egg-shaped tablets", muito próximos das bullae) e por pequenos objetos que podiam ser agrupados, separados, contados, armazenados, descartados, segundo as necessidades da administração (operações a que os próprios textos faziam menção) $)^{4}$.

Alguns anos mais tarde, Pierre Amiet publicava um artigo seminal, mostrando que, em Susa, existira um sistema semelhante, associando tokens e bullae, que precedera o aparecimento dos primeiros tabletes inscritos. De um golpe, Amiet deslocava o fenômeno para o quarto milênio e propunha interrelações inéditas com o aparecimento da escrita e com o dinamismo urbano do período de Uruk, particularmente a circulação de bens e suas conseqüentes necessidades notariais (Amiet, 1966, p. 22). 
A essas inspirações iniciais, Schmandt-Besserat acrescentou, ao longo das décadas de 70 e 80 , um intenso trabalho de coleção e interpretação de material arqueológico proveniente de dezenas de sítios médio-orientais (os tokens foram identificados em mais de 100 sítios, 43 deles na Mesopotâmia; em Uruk, foram encontrados cerca de 850 desses objetos). A síntese por ela proposta avançou no sentido de uma explicação do funcionamento dos sistemas pré-históricos de registro e de suas relações com o aparecimento da escrita cuneiforme ${ }^{5}$.

O primeiro estágio é representado pelos tokens isoladamente. Emergindo por volta de 8000 a.C. ${ }^{6}$, um sistema baseado nesses pequenos dispositivos mnemônicos parece ter se expandido por um considerável arco geográfico nos milênios seguintes: o vale mesopotâmico, a Síria e o Irã, mas igualmente o Egito (Khartum e Abydos), a Turquia (Beldibi), a Palestina (Jericó) e o vale do Indo (Chanhu Daro). Durante aproximadamente quatro milênios, os tokens conservaram sua característica originalmente lisa, com predomínio de certas formas geométricas (cones, esferas, discos, cilindros, tetraedros, ocasionalmente ovóides, triangulares, retangulares...), ocorrendo, todavia, algumas poucas formas naturalísticas. O passo seguinte representou um ganho de complexidade dos próprios tokens: diversificação das formas, geométricas ou não, presença de incisões e perfurações. Esses "complex tokens", que se somam aos mais simples sem jamais substituí-los, são característicos do quarto milênio, quando justamente se consolida a importância de Uruk como principal centro urbano mesopotâmico. É ainda durante o quarto milênio que os tokens passarão a ser envelopados em recipientes esféricos de argila. As bullae permitem um melhor controle físico do procedimento de contagem e de armazenamento da informação representada por um conjunto de tokens. Nesse estágio, ocorre um passo essencial na linha evolutiva que levaria à escrita: a superfície das bullae recebe a impressão de selos e, em muitos casos, dos tokens por elas contidos. Significa dizer que a relação de referência é acrescida de um grau suplementar: a imagem impressa, bidimensional, remete ao objeto referenciado (uma mercadoria, um animal, uma quantidade de cereal) através da intermediação dos tokens tridimensionais. O novo salto envolverá o segundo componente essencial da relação de referência implicada pelo sistema: a computação. Desde seus primórdios, não há dúvidas de que o artifício se assentava nesta dupla capacidade referencial, a um só tempo qualitativa e quantitativa (o que, de passagem, significa que, mesmo em seus estágios iniciais, comportava uma alta dose de abstração). No entanto, a relação outrora supostamente simples - um token valendo por um objeto ou por uma quantidade estabelecida - cede lugar a um repertório completo, autônomo e sistemático de contagem, assentado em uma conotação propriamente numérica (uma marca remete, agora, a uma unidade abstrata de quantidade, já não vinculada necessariamente a um bem específico). É o que caracteriza os chamados tabletes numéricos ${ }^{7}$. É interessante notar como os suportes materiais do sistema acompanham os avanços conceituais: as bullae ocas são substituídas por tabletes compactos; por decorrência, os tokens desapare$\mathrm{cem}^{8}$, definitivamente substituídos pelas notações feitas na superfície do tablete, por si só capazes de registrar e comunicar qualidades, quantidades e operações; os selos continuam acrescentando informações de identificação, que remetem a pessoas, ocupações funcionais, esferas da administração. O signo, agora, é o vetor absoluto dos significados, num quadro que congrega todos os elementos necessários para levar ao estágio final da linha evolutiva proposta por Schmandt-Besserat: a escrita cuneiforme.

Desde o início, o esforço de Schmandt-Besserat visava oferecer uma resposta ao problema do caráter pictográfico dos primórdios do cuneiforme mesopotâmico. De fato, ao 
contrário do que se pensa normalmente, a presença dos signos pictográficos no repertório dos tabletes arcaicos de Uruk é extremamente pequena e, além disso, associada a um vocabulário de uso pouco corrente (como variedades de pássaros, carros de guerra etc.), o que fez com que, desde os primórdios do deciframento, o caráter pictográfico dos antecedentes dos sinais cuneiformes fosse objeto de um acirrado debate ${ }^{9}$. Mais recentemente, há os que procuraram minimizar o papel dos sinais pictográficos no processo de constituição do sistema cuneiforme, conferindo prioridade aos signos abstratos, cuja relação de referência é totalmente convencional (uma possibilidade seria, então, que a notação das palavras tivesse sido uma transposição, em outra chave, dos mesmos princípios que norteavam a notação dos números (cf. Nissen, 1997, p. 29). Outros, ainda, propõem que os antecedentes da relação pictográfica seriam simplesmente inacessíveis do ponto de vista documental; assim, os primeiros tabletes seriam o resultado de um longo processo de maturação experimentado sobre suportes perecíveis - madeira, fibras vegetais etc. (cf. Lieberman, 1980, p. 358). Para Schmandt-Besserat (Schmandt-Besserat, 1978, p. 38 ss.), entretanto, é justamente a linha de ascendência que leva até os tokens que explica as características dos tabletes de Uruk (sua composição majoritária por sinais abstratos e sua residual carga de iconicidade) o que, em outros termos, significa que representam o estágio avançado de um sistema já milenar, mais do que os primeiros passos de uma novidade.

Nas reservas levantadas à genealogia proposta por Schmandt-Besserat, a questão não é das menos importantes. Stephen Lieberman (Lieberman, 1980), por exemplo, embora aceitasse a existência de um sistema de contagem, registro e controle baseado nos tokens, rejeitou que ele tivesse a amplitude icônica sugerida pela autora. Assim, apenas alguns dos pequenos objetos teriam cumprido essa função (justamente, os que apareceriam tardiamente gravados na superfície das bullae): somente esses, então, teriam funcionado como signos no interior de um sistema sígnico icônico, ou seja, remeteriam, por substituição, a um conteúdo ausente (ao menos do campo visual externo às bullae). Mais particularmente, operariam uma relação de referência assentada na aparência formal, em que a analogia plástica era determinante, como nos verdadeiros ícones. Daí deve ter derivado, prossegue Lieberman, o sistema curvilíneo de notação numérica, que, durante o terceiro milênio conviveu, às vezes no mesmo tablete, com a escrita cuneiforme e com uma segunda notação numérica, também cunciforme. Seriam, portanto, sistemas autônomos e paralelos, a escrita tendo um caráter totalmente diferente: sua relação de representação não é icônica, mas simbólica. O sinal cuneiforme opera em um sistema de signos de outra natureza, em que o significado é estabelecido arbitrariamente e compactuado culturalmente ${ }^{10}$. Nesta perspectiva, ainda que possa haver relação entre os dois sistemas (os tokens e os números curvilíneos sugerindo a idéia de representação das quantidades para o sistema cuneiforme), não caberia pensar em derivação genética. Uma das manifestações concretas da distância entre os dois sistemas seria o fato de que apenas para um número reduzido de sinais cuneiformes pode-se estabelecer uma analogia com a aparência dos tokens. E, mesmo assim, as comparações são apenas formais não levando em consideração o uso e a trajetória posterior do sinal cuneiforme. Por isso, em muitos casos, as identificações propostas por Schmandt-Besserat parecem insustentáveis para Lieberman, quer porque um único sinal fora comparado a vários objetos, quer, pelo contrário, um só objeto fora vinculado a muitos sinais.

Outra objeção situa-se no nível da articulação entre escrita e língua. Embora estejamos acostumados a estabelecer uma relação imediata, definindo a escrita como um sistema gráfico de expressão da língua, as circunstâncias que envolveram o aparecimento do 
e gênese da escrita cuneiforme.

cuneiforme mostram uma situação bem mais complexa. Em primeiro lugar, porque nada garante a vinculação entre os primeiros sinais (o chamado proto-cuneiforme) e a expressão verbal, e muito menos com uma língua em particular ${ }^{1 !}$. No entanto, quando esta relação se torna inquestionável, e o sumério se mostra como a língua por trás do texto cuneiforme, a distância face aos pressupostos antecedentes não pode ser minimizada e a transição deve ser explicada. Por isso mesmo, alguns autores, como Herman Vanstipihuot (Vanstipihuot, 1995), apontaram a falha da teoria de Schmandt-Besserat em atentar para as diferenças de natureza, e não apenas de grau, entre os dois sistemas. Vanstipihuot sugere mesmo um abismo intransponível entre a notação contábil e o cuneiforme propriamente dito, uma vez que nem os tokens nem as bullae possuiriam duas características essenciais à escrita: a capacidade de notação fonêmica e de sintaxe gramatical. A esse propósito, convém lembrar que, nos tabletes proto-cuneiformes, a articulação entre os elementos é indubitavelmente espacial, carecendo de qualquer arranjo sintagmático gramatical ${ }^{12}$. A resposta dependerá, em grande parte, da caracterização que se faça da própria escrita cuneiforme: Marvin Powell (Powell, 1981, p. 420 ss.), por exemplo, enfatizou seu aspecto mnemônico, isto é, análogo ao sistema de tokens/bullae, em detrimento da dimensão logográfica, por sua vez ressaltada por trabalhos clássicos, como o de Ignace Gelb (Gelb, 1952). É de se notar o argumento de Powell sobre a persistência do caráter mnemônico mesmo nos milênios posteriores, em que o sistema cuneiforme já contava com um repertório fonético suficiente para expressar a língua, mas nunca abandonou totalmente os ideogramas ${ }^{13}$.

Outras dificuldades foram levantadas por Piotr Michalowski (Michalowski, $1990 \mathrm{e}$ 1996), algumas referentes ao controle dos dados a partir do contexto arqueológico e sua interpretação funcional. $\mathrm{O}$ autor vê sérias dificuldades em aceitar a ampla difusão proposta por Schmandt-Besserat, menos porque pareça geograficamente insustentável, mas por pressupor a existência de um mesmo sistema comunicativo que atravessaria uma incrível diversidade cultural, o que lhe faz preferir, igualmente, a hipótese de uma origem localizada da escrita. Além disso, Michalowski questiona a identificação da totalidade dos tokens com uma única categoria e, conseqüentemente, função ${ }^{14}$. Lieberman (Lieberman, 1980) também havia posto em dúvida a abrangência pretendida por Schmandt-Besserat e considerado falso o pressuposto de que os tokens correspondessem a um repertório estável de formas e tamanhos, como seria requerido por um sistema de comunicação que tivesse atuado como uma verdadeira língua franca na pré-história do Médio-Oriente.

Uma posição mais moderada tem sido sustentada pelos pesquisadores ligados ao projeto dos tabletes arcaicos de Uruk, da Universidade Livre de Berlin ${ }^{15}$. Em geral, esses autores aceitam a genealogia proposta por Schmandt-Besserat, mas procuram resguardar uma certa originalidade da escrita cuneiforme, como se esta não fosse totalmente explicável pela sua ascendência. Hans Nissen, por exemplo, apresenta-a como "o último elo de uma cadeia milenar de esforços do homem para criar meios mnemotécnicos" (Schmandt-Besserat, 1997, p. 30), mas reafirma seu caráter de resposta individual a problemas particulares enfrentados em um contexto delimitado. Vê-se que a hipótese da invenção individualizada ganha um novo fôlego, agora acoplada a uma lógica menos casuística e aleatória ${ }^{16}$. Por seu lado, Robert Englund, que havia criticado duramente vários pontos da tese de SchmandtBesserat (Englund, 1993), acabará por considerar correta a linha evolutiva por ela sugerida, reforçando, especialmente, os vínculos entre a escrita e os procedimentos de controle contábil (Englund, 1998). Como o projeto de Berlin está em pleno desenvolvimento, parece que os autores resistem a fechar as portas para novidades que possam alterar os rumos das considerações sobre o aparecimento da escrita cuneiforme ${ }^{17}$. 
Apesar das reservas e oposições, a teoria de Schmandt-Besserat logrou tornar-se, no decorrer da década de noventa, a visão dominante sobre o tema ou, ao menos, a referência mais importante do debate, sem que nenhuma outra disputasse sua primazia ${ }^{18}$. A alternativa consistiu, grosso modo, em um revisionismo que negou toda vinculação com os sistemas de controle e conservou a escrita como um fenômeno relativamente isolado (de onde a ênfase na noção de invento). Apenas eventualmente um outro caminho foi apontado: por exemplo, Malati J. Shendge (Shendge, 1983), propôs uma genealogia alternativa, que partia não dos tokens e das bullae, mas das impressões de selos e das notações numéricas. No entanto, apesar de os estudos sobre a função social dos selos terem se multiplicado nos últimos anos, definindo seu lugar no quadro dos dispositivos de comunicação, a proposta de Shendge restou isolada.

Por outro lado, a existência de sistemas pré-históricos de contabilidade baseados nos tokens e, às vezes, nas bullae tem tido uma acolhida ampla, mesmo entre os que rejeitaram enfaticamente a derivação da escrita. O mesmo M. J. Shendge (Shendge, 1985), por exemplo, crê que a hipótese pode ser aplicada a Harappa, no vale do Indus (em que foram encontrados apenas tokens), num desenvolvimento cronologicamente paralelo ao de Susa e Uruk, em fins do quarto milênio. Este é, aliás, um aspectos das idéias de Schmandt-Besserat que tem sido transposto para áreas não previstas inicialmente: baseado nos dados arqueológicos de Mália, J.-Cl. Poursat (Poursat, 1994) sugeriu que um sistema contábil baseado nos tokens teria funcionado no fim da época dos primeiros palácios em Creta. Embora os prováveis tokens cretenses (especialmente, vasos em miniatura) tivessem características bem distintas das dos seus equivalentes médio-orientais, teriam sido igualmente parte de um mecanismo de controle preponderantemente econômico, centrado em organismos complexos e associado a outras técnicas de registro, como os selos e os tabletes inscritos.

\section{Escrita e complexidade social}

As vinculações entre o aparecimento da escrita e o aumento da complexidade social no quadro do chamado "processo civilizatório" foram frequientemente reconhecidas. Em particular, foram acentuadas as várias transformações econômicas e sociais tidas como mais imediatamente ligadas ao grafismo, tais como a necessidade de gerenciamento dos dados econômicos por parte das grandes organizações, o controle do fluxo interno e externo de bens, a diversificação das relações e dos procedimentos de controle da mão-de-obra gerada pelo acréscimo da divisão social do trabalho etc. A própria teoria de Schmandt-Besserat implicava, obviamente, uma ênfase nesses aspectos. Embora em menor grau, as articulações com os fatores políticos também foram lembradas: a escrita como componente da centralização do poder, da própria formação do estado e de sua intrínseca propensão à regulamentação dos discursos ou o papel da escrita como tecnologia do poder, vetor de formas de dominação. Por último, ainda que de maneira pouco sistemática, chamou-se a atenção para a intersecção com as estruturas mentais e, em alguns casos, para as implicações da aquisição da literalidade no processo cognitivo, individual e coletivo. A exceção a esse tratamento fluido deu-se, sem dúvida, no campo da religião e da mitologia, em que os interesses dos especialistas se concentraram precocemente. No entanto, mesmo aí, as articulações reduziram-se quer a uma eventual função mágica ou ritual das primeiras tentativas de grafismo ${ }^{19}$, quer ao reconhecimento, quase universal, de um atraso considerável das rela- 
ções entre a escrita e a religião (ou a mitologia), concordando, assim, com um uso primário pragmático, na economia e na administração, e uma migração tardia para o universo simbólico.

A divergência quanto ao caráter utilitário dos primeiros registros escritos orientou, como se vê, todo um aspecto do debate. Uma corrente majoritária foi sintetizada por Jean Bottéro (Bottéro, 1987), que realçou o caráter mnemônico dos primeiros estágios e seu uso predominante como um dispositivo econômico-admnistrativo. Nesta perspectiva, a escrita aparece, em seus estágios iniciais, como uma técnica de registro de informações que confere ao homem um considerável aumento na capacidade de armazenamento e manipulação dos dados, em uma situação de complexidade crescente. Tendo se concentrado nas práticas contábeis dos templos e palácios, registrando a entrada e saída de bens, as oferendas, a distribuição de víveres ao pessoal administrativo etc., apenas por volta de 2600 a.C. o sistema ganharia maleabilidade suficiente para ser aplicado a outros campos, como as inscrições reais, as narrativas mitológicas, os hinos e preces aos deuses e, ainda mais tarde, as manifestações do cotidiano, como as cartas.

Uma série de argumentos já haviam sido levantados contra a tese utilitarista por Jean-Marie Durand (Durand, 1977). Ainda que reconheça sua suposta lógica, Durand acredita que a visão tradicional não pode ser sustentada pelas evidências documentais. $\mathrm{O}$ autor lembra que, dentre os primeiros textos decifráveis de Shuruppak, já estão presentes exemplares não-econômicos e que nada impede que assim seja também em relação aos tabletes anteriores, ainda não elucidados. Aponta, igualmente, que outros tipos de escritos, tão necessários quanto os registros econômicos, só aparecem tardiamente e, em certos casos, na periferia mesopotâmica, como os tratados internacionais, surgidos no ambiente hitita em meados do segundo milênio a.C. Por fim, acrescenta que, apesar das aparências, uma parte dos textos não está ligada à necessidade econômica, mas às manifestações simbólicas das camadas elevadas da sociedade, como, por exemplo, os primeiros registros escritos das operações imobiliárias: em sua opinião, um suplemento ao procedimento oral, feito simplesmente por razões de prestígio. Embora as considerações de Durand tenham o mérito de pôr em causa a "razão utilitária", abrindo caminho para outras interpretações (que ele próprio, porém, não percorre), seus argumentos não parecem convincentes, por três motivos: em primeiro lugar, baseiam-se em uma projeção sobre as origens, no quarto milênio, das características sociais que a escrita assumiu no decorrer de sua existência posterior: Durand avaliou a questão das origens com os olhos voltados para a trajetória posterior do cuneiforme; em segundo lugar, definida a partir das evidências documentais legíveis, sua noção de escrita é extremamente restritiva, confundindo-se com o texto e impedindo de situar devidamente seus antecedentes pré-lingüísticos; por fim, o fenômeno da escrita ganha uma autonomia exorbitante, desencarnando a gênese de seu contexto histórico.

O principal entrave, porém, encontra-se nos próprios termos que definiram o debate. De fato, a oposição utilitário/não-utilitário, bem como seu desdobramento no par econômico/não-econômico, não é metodológica e teoricamente operacional em todos os casos, e não parece ser neste, o que dificulta a apreciação adequada das articulações entre a escrita e os demais fenômenos sociais. Parece-me importante estabelecer, aqui, uma distinção entre o setor prioritário da aplicação inicial do grafismo (no caso mesopotâmico, indubtavelmente as esferas institucionais da produção, da distribuição, do armazenamento, do consumo) e o conjunto mais amplo de impulsos que levaram ao acirramento das transformações no decorrer do quarto milênio e que estiveram na origem da escrita. Essas duas realidades manifes- 
tam-se de forma desigual na documentação, o que obriga a reconhecer que os primeiros exemplares da escrita cobrem apenas um setor limitado dos múltiplos dispositivos de controle postos em marcha no final do neolítico.

A questão que precede, portanto, é a do controle; a primazia da economia é apenas uma sua manifestação histórica particular. O fato de os primeiros exemplares da escrita mostrarem um uso prioritariamente econômico não deve ocultar que a utilização do sistema pressupunha uma transformação social, política e cognitiva sem precedentes. O aumento da complexidade social, em si um fenômeno plural, engendrou uma grande diversidade de mecanismos de controle, o que já nos informa sobre a natureza do processo, uma vez que estão em função direta do acesso diferenciado aos recursos, da disposição não apenas desigual mas também hierarquizada das camadas sociais, da mediação das relações entre o homem e a natureza e entre o homem e o sobrenatural. O controle significa um esforço de ordenamento das relações diferenciadas. Quanto mais distante a sociedade se encontra do igualitarismo ${ }^{20}$, quanto maior o grau de mediação das relações sociais, maior a necessidade de instrumentos de controle: a escrita é apenas um dentre outros.

Por seu lado, os diversos mecanismos de controle têm aplicações distintas, ou, ao menos, zonas preferenciais de existência. Em muitas situações históricas, alguns deles, extremamente importantes, não se lastreiam em registros escritos. Isso em nada diminui o seu papel: apenas indica que o seu ingresso no horizonte da palavra escrita não foi exigido pelo processo social. Poderíamos enquadrar nessa categoria uma infinidade de regras tácitas de comportamento do indivíduo em sociedade, as normatizações que dispõem sobre a expressão corporal, algumas das muitas táticas de sujeição operadas pelo poder etc. ${ }^{21}$. Outros, ao contrário, manifestaram-se através de um registro gráfico, lingüístico ou não. O mais provável é que alguns desses procedimentos de controle tenham, ao cabo de um longo processo, esgotado suas possibilidades, exigindo uma reformulação ou mesmo a alteração profunda de suas características (se o raciocínio for correto, o primeiro caso se concretizou com a passagem dos tokens simples aos tokens complexos e bullae; o segundo, com o aparecimento da escrita). No caso mesopotâmico, a protelação do uso da escrita nos domínios extraeconômicos foi menos uma conseqüência das dificuldades enfrentadas pelo sistema em superar os entraves técnicos para a expressão da língua (o que, de qualquer forma, não deve ser menosprezado) e mais a decorrência de que, durante os séculos de gênese das organizações complexas, a maior parte dos processos de controle operou-se no nível do discurso oral ou iconográfico.

Esse desequilíbrio entre o fenômeno histórico e a documentação historiográfica não tem sido devidamente considerado, em parte pela importância desmedida conferida à escritura pelos historiadores. O seu reconhecimento, no entanto, leva a concluir que a prioridade do controle econômico, materializada pelos registros escritos, é uma manifestação localizada (e que tem implicações de ordem documental), a não ser confundida com o conjunto da realidade. Assim, a tese de que a escrita foi uma consequiência do jogo econômico tem o mérito de delimitar o que foi inquestionavelmente o campo privilegiado de seu uso efetivo. Ao mesmo tempo, a crítica anti-utilitalista nos faz reconhecer que o processo por trás da gênese do grafismo é mais extenso e complexo, não podendo ser deduzido a partir de uma evidência documental limitada ${ }^{22}$.

A tese aqui defendida pressupõe uma linha de continuidade entre os impulsos geradores e as primeiras aplicações da escrita. Uma visão alternativa, no entanto, foi proposta por Jean-Jacques Glassner (Glassner, 1998), segundo a qual há uma clivagem entre as in- 
e gênese da escrita cuneiforme.

tenções criadoras (situadas na vontade de apreensão pelo conhecimento, de classificação categorizada do real, ou mesmo de transposição para um sistema semiológico legível pelo homem das marcas divinas) e os usos iniciais do sistema. Os registros econômicos seriam, assim, um modo de expressão parcial de um aparato cognitivo mais amplo, externo à atividade administrativa, aplicado a ela secundariamente. A meu ver, embora estimule a reflexão sobre pontos interessantes (como o papel da escrita na passagem de um poder colegiado de elite a um poder monárquico, progressivamente tornado hereditário), a linha de pensamento de Glassner bloqueia a possibilidade de se entender o papel das necessidades administrativas das organizações complexas no surgimento e consolidação da prática da escritu$\mathrm{ra}^{23}$.

A consideração de alguns fatores ajuda a entender seja o contexto histórico, seja a situação documental acima referidos. Em primeiro lugar, foram os templos e palácios que captalizaram a liderança do processo, isto é, ofereceram o enquadramento para a reestruturação da sociedades do Bronze. Ora, esses organismos formaram os pólos centrais da nascente economia redistributivista. A captação de parte dos bens produzidos pelos produtores diretos e sua canalização para as camadas não-produtoras, bem como outros procedimentos de re-alocação dos recursos tornaram-se essenciais. Ademais, os próprios templos e palácios controlaram setores extensos da vida econômica. Não é de espantar que, nesse quadro, a escrita tenha nascido sob a égide dos impulsos contábeis e dos hábitos notariais ${ }^{24}$.

É verdade que templos e palácios foram igualmente instituições políticas, religiosas, culturais. Mas o desequilíbrio quanto ao uso da escrita e seu descompasso cronológico explicam-se por uma diferença de natureza entre os discursos por eles manipulados. Na esfera econômica, o aumento da complexidade gerou uma carga de informações (dados e operações) que rapidamente extrapolou a capacidade de armazenamento pela memória, de registro pelos meios tradicionais (inclusive tokens e bullae) e de transmissão pela fala, como ocorria nas sociedades pré-históricas. Ainda mais, não se tratava apenas de um problema de quantidade, mas também de forma de gerenciamento no decorrer do tempo: muitos dados, como o registro de entradas e saídas de grãos ou o controle da perecibilidade dos alimentos, passaram a mudar rapidamente, a cada estação, a cada mês ou a cada dia; outros, ao contrário, exigiram uma manutenção das informações por vários anos, como o rendimento de pomares arrendados a longo termo ou o recebimento de juros. Essa nova dinâmica superou em muito a capacidade dos sistemas de contagem em vigor, exigindo a inovação. Nos demais setores, em que os discursos, pelas suas próprias naturezas, tendiam a ser mais estáveis e formulares, a pressão em direção a escrita foi menor. É o caso, por exemplo, das narrativas mitológicas, em que a utilização de certos recursos mnemômicos (como as cadências ritmadas, as diversas formas de rima etc.) permitiu um prolongamento de práticas exclusivamente orais. Um terceiro aspecto: o setor administrativo foi aquele em que mais rapidamente se impôs a ruptura entre o produtor do discurso e o próprio discurso. Foi onde a validade dos registros cada vez mais exigiu uma autonomia em relação à pessoa e ao momento da fala. $\mathrm{A}$ escrita conferiu legitimidade e autoridade ao registro contábil, permitindo que ele circulasse nas esferas de controle, independentemente de seu criador. Pelo contrário, o discurso mitológico ou mesmo o discurso político conservaram-se ainda por algum tempo atrelados à autoridade de quem o pronunciava e ao ato do pronunciamento.

Não parece, tampouco, que se possa falar de continuidade material e ruptura intelectual entre os sistemas pré-históricos e a escrita. Há, nos dois campos, inovações profundas que significaram uma superação das antigas formas, mas há igualmente sequiências 
ininterruptas. Do ponto de vista formal, por exemplo, embora nem todo o conjunto de signos que compunha a escrita possa ser explicado a partir dos tokens, o cuneiforme assimilou uma série de suas características. Por outro lado, no entanto, a própria passagem da impressão à incisão implicou uma ruptura importante: enquanto a impressão significava a transferência para um outro suporte de referenciais concretos que existiam fisicamente exteriormente a ele (o que acarretava uma limitação do repertório e uma intermediação rígida entre o tablete impresso e o pensamento), a inscrição, por sua vez, livrava de um intermediário a intenção do registro: não se trata de um segundo momento do ato gráfico, mas do momento criador; a inscrição sobre o tablete passou a fazer parte do próprio processo de elaboração da mensagem. De igual modo, também no campo cognitivo percebem-se continuidades e rupturas. A escrita compartilha a intenção comunicativa geral e específica dos sistemas contábeis anteriores, mas se situa num ponto de inflexão em que aqueles devem ser ultrapassados por um sistema no qual as capacidades logográficas não mais estejam situadas nas bordas, mas do coração do procedimento. Permitindo, por isso mesmo, que a escrita não se limite a um artifício mnemônico ${ }^{25}$.

Um outro aspecto a considerar é o fato de que nossas categorias não correspondem exatamente àquelas dos antigos mesopotâmios. Assim, mesmo quando identificamos uma aplicação inicial mais estreita da escrita na esfera econômica, apenas nos aproximamos de uma realidade bem mais nuançada. Especialmente no que diz respeito à categoria do econômico, é preciso reconhecer, na seqüência dos trabalhos de Karl Polanyi, que não se trata de um campo de relações com a mesma autonomia que mostrará mais tarde, sob o capitalismo. A atividade econômica e suas derivações, como os registros contábeis, inscrevem-se no todo social de um modo diferente. Equivale dizer que, em uma situação em que parte considerável dos movimentos de alocação dos bens tem caráter de oferenda ritual ou de consumação divina, os registros contábeis são, ao mesmo tempo, um fenômeno econômico e religioso. A mesma indistinção se verificará, por exemplo, quanto às relações entre comércio e política, apropriação do solo e concepções mitológicas etc.

Detenhamo-nos, ainda um instante no processo de aumento da complexidade social no quarto milênio.

Desde a década de setenta, os trabalhos de R. McC. Adams e H. Nissen (Adams \& Nissen, 1972) tinham demonstrado, a partir da análise dos padrões de assentamento, o incremento populacional da região de Uruk, que se beneficiara de um êxodo de habitantes das localidades mais ao norte, Adab e Nippur, por exemplo (cf. igualmente Adams, 1981, p. 63 ss.). Os movimentos demográficos, então, parecem ter atuado de um modo decisivo e, por volta de 3300, Uruk será o maior aglomerado do planeta. Não se trata, porém, tão-somente de um crescimento quantitativo, mas sobretudo de uma transformação na forma de ocupação do território, de aproveitamento dos recursos e de organização social: em uma palavra, o processo de urbanização. Outros autores salientaram a emergência das estruturas hierárquicas de administração e o papel das trocas inter-regionais (Wright \& Johnson, 1975, para o sudoeste iraniano), além do incremento da estratificação social que acompanhou a diferenciação política (Zagarell, 1986). Mais recentemente, Guillermo Algaze (Algaze, 1993) buscou delinear as características do processo a partir de uma abordagem que posicionava Uruk como o centro de uma rede de contatos inter-regionais, baseados nas trocas de longa distância. Impulsionada pelo contraste entre a carência de certos materiais (como pedras, metais e madeiras) e a riqueza agrícola e pastoril do vale em que se situava, Uruk teria se transformado no pólo articulador de um sistema-mundial de relações diferenciadas, impon- 
do uma dependência, prioritariamente econômica, a localidades que se espalhavam de Susa à Síria e à Anatólia (cf. também Frank, 1993) ${ }^{26}$. Amenizando o peso dos fatores materiais, Roger Matthews (Matthews, 1997, p.15 ss.) argumentou que a expansão de Uruk pode ter sido o resultado de um impulso evangelizador de uma religião nova ou de atividades rituais enraizadas em uma política dominadora e elitista (neste caso, a escrita não seria apenas um meio de administração, mas um instrumento de controle no interior de um sistema político mediatizado pelo ritual religioso).

As visões acima estão longe de esgotar o problema e nem sempre são compatíveis entre si. Ao citá-las, apenas quero chamar a atenção para a diversidade do contexto social em que se originou a escrita. Embora, em certos casos, seja surpreendente a falta de reflexão acerca das relações entre escrita e complexidade (como é o caso de Algaze), em geral, tem se apresentado a aquisição do grafismo como uma decorrência da conjunção de diversos fatores, dentre os quais nem sempre é possível, ou desejável, discernir uma causa principal. Dois acréscimos poderiam ser feitos. Em primeiro lugar, essa manifesta diluição dos fatores que levaram ao aparecimento escrita não deve ser vista como uma incapacidade da pesquisa em definir mais precisamente as causas singulares: trata-se, antes, de um dado inscrito na própria natureza do fenômeno sob análise. Em segundo lugar, a identificação da escrita como o produto de uma série de fatores conjugados e o reconhecimento de sua funcionalidade primariamente econômica não esgota o seu papel, uma vez que, a partir de sua adoção como um sistema de comunicação socialmente relevante, ela passa quer a fazer parte do processo de complexidade quer a ter implicações inimagináveis sem um dispositivo de registro gráfico do pensamento e da língua.

Não é o caso, entretanto, de falar das “conseqüências da literalidade" nos termos de certa tendência da antropologia, que se firmou a partir das décadas de sessenta. Sobretudo, os primeiros trabalhos de Jack Goody contribuíram para a construção de uma visão em que a escrita tinha uma autonomia desproporcional como elemento causal da complexidade e de diferenciação entre tipos de sociedades (Goody \& Watt, 1963). Nos desdobramentos do debate, o próprio Goody tratou de amenizar sua proposta inicial, preferindo falar de "implicações da literalidade" (Goody, 1986) ${ }^{27}$. As hesitações revelam a dificuldade em posicionar a escrita entre os demais fenômenos socias. Quanto à antiga Mesopotâmia, Margareth Green (Green, 1981), por exemplo, salientou que, embora o grafismo tivesse sido introduzido em uma situação que já demonstrava alto grau de complexidade, contribuiu decisivamente para a consolidação e o desenvolvimento de certas características, em particular, a administração centralizada e a autoridade sobre o pessoal administrativo. A recusa em estabelecer uma monocausalidade e, por outro lado, em dotar a escrita com atributos matriciais desmesurados parece-me ser um avanço considerável (cf. especialmente Larsen, 1988). É neste sentido que considerar a escrita como um fator de capacitação (enabling factor), mais do que como uma condição suficiente para o que quer que seja, permite conduzir o debate a patamares mais adequados ${ }^{28}$. A partir daí, longe de se resolverem as questões pendentes, abrirse-ia para a pesquisa todo o campo, ainda deficientemente explorado, das práticas sociais da escritura e das interfaces entre a oralidade e literalidade na Mesopotâmia antiga ${ }^{29}$.

Uma reconsideração da posição da escrita no interior do processo de aumento da complexidade social em fins do quarto milênio permite melhor situar os três pólos da equação proposta no título deste artigo.

Pode-se dizer em vias de superação uma abordagem que, definindo a escrita a partir da excepcionalidade de um invento genial, acabava por extirpá-la de seu contexto e esvaziá-la 
de seu significado histórico, contraditoriamente sob o argumento de conferir-lhe importância. Vê-se bem como o exemplo mostra que o grau de relevância dos fenômenos individuais só pode ser aferido dentro de um quadro de referências históricas. É, pois, justamente a dessacralização da escrita, a negação de seu caráter epifenomênico, que permite compreender seu papel, os impulsos que a geraram e as perspectivas inovadoras que ela inaugurou.

Paradoxalmente, sua inserção em uma linhagem de dispositivos de registro que data dos inícios do neolítico leva a reconsiderar não apenas o conceito de complexidade, mas, como lembrou Mario Liverani (Liverani, 1994, p. 416), sua própria cronologia e distribuição espacial. De fato, ao menos alguns dos elementos parecem remontar a milênios antes da "revolução urbana". Ainda que isso não signifique negar a primazia do quarto milênio como momento de concentração máxima das transformações, uma re-orientação do foco poderia delinear mais claramente os antecedentes.

Por fim, a escrita não deve ser vista, na sequiência de uma avaliação equivocada do material documental à nossa disposição, como um meio de comunicação exclusivo ou mesmo hegemônico. Pode-se dizer que o processo de aumento da complexidade social em fins do quarto milênio foi acompanhado de uma acentuada proliferação dos sistemas semiológicos, alguns inéditos como a escrita, ou da diversificação de suas formas de expressão, como mostra o surgimento dos selos cilíndricos ${ }^{30}$. Os novos sistemas comunicativos são, portanto, a materialização de um impulso de representação das relações geradas no quadro de transformação das sociedades neolíticas em vias de urbanização.

\section{Notas}

1 - O presente artigo retoma e aprofunda uma palestra apresentada ao Congresso da SBEC de 1997, sobre as Escritas no Mundo Antigo, cuja publicação é objeto deste volume. Meus agradecimentos à Profa. Dra. Haiganuch Sarian pelo convite para substituir o Prof. Dr. Emanuel Bouzon, momentaneamente impedido na ocasião.

2 - Vinte e cinco dessas esferas foram encontradas no sítio de Warka durante a campanha de 1962-3 e publicadas mais tarde por H. J. Lenzen (Lenzen, 1965, p 1 ss., fig.17-19a). Para o quadro que se vai aqui estabelecendo, é importante, notar que sua datação (Uruk IVc) mostrou serem anteriores ao aparecimento dos primeiros tabletes inscritos.

3 - Como notou P. Amiet (Amiet, 1994, p. 95), não deixa de ser um interessante reconhecimento do caráter de pictograma de três dimensões, o que deveria ser explorado mais tarde por inúmeros especialistas. Certamente a interpretação de Mecquenem foi influenciada pela concentração dos objetos em tumbas infantis. Por outro lado, um problema particular dos trabalhos na acrópole de Susa foi a cronologia. No que nos concerne, por exemplo, Mecquenem datou os tokens do período de Acade, bem posterior, o que, por muito tempo, impossibilitou que se percebesse o sincronismo entre Susa e Uruk (cf. Amiet, 1994). Embora J. Jordan e H. J. Lenzen não tardassem a reconhecer a similaridade entre os achados dos dois sítios, apenas em 1957 L. de Breton logrou estabelecer uma correspondência mais adequada entre as estratigrafias; ainda assim, no decorrer da década de sessenta, os escavadores de Uruk continuavam ludibriados pelas datações equivocadas de seu colega de Susa (cf. por exemplo, Lenzen, 1965, p. 31 ).

4 - A partir da referência textual (a palavra utilizada é sempre $a b n u=$ pedra, grafada a partir do sumerograma $\mathrm{NA}_{4}$ ) e arqueológica, Oppenheim estabeleceu imediatamente o parale- 
e gênese da escrita cuneiforme.

lo com os sistemas de conta das fontes latinas (calculi) e das evidências etnográficas do Daomé, estudadas pelo antropólogo J. Herskovits.

5 - A enorme quantidade de publicações da autora tem isso de característico: freqüentemente retoma, aprofunda ou mesmo corrige os mesmos tópicos. Para evitar redundâncias, dispensarei as referências particulares, limitando-me a oferecer uma visão geral de sua tese. Para uma lista dos principais trabalhos, ver a bibliografia; uma síntese pode ser encontrada em (1992, vol.I). Não é sem interesse notar que Schmandt-Besserat havia freqüentado a Escola do Museu do Louvre, onde P. Amiet era o diretor das Antigüidades Orientais. Trabalhando paralelamente a Schmandt-Besserat, e também seguindo os passos de Amiet, Mark A. Brandes chegou a conclusões muito próximas às da autora norteamericana (cf. Brandes, 1980).

6 - A própria autora hesita em situar o marco inicial da utilização dos tokens entre o nono milênio e meados do oitavo milênio.

7 - É uma tendência, todavia, incompleta, que não deve ser exagerada: sabemos que pelo menos cinco sistemas diferentes de cômputo eram usados nesse estágio, alguns marcadamente vinculados a certos tipos de bens, grãos por exemplo, ou medidas particulares, como área ou tempo (cf. Damerow \& Englund, 1987, p. 126 ss.).

8 - A sobrevivência no caso de Nuzi, ainda nos meados do $\mathrm{II}^{\circ}$ milênio, é certamente residual e periférica, estando longe de ser o único traço de arcaísmo da região de Arrapha.

9 - Para um resumo, ver S. A. Pallis (Pallis, 1956, p.188 ss.). No mais, a questão foi mais um ingrediente da discussão, por vezes nada científica, acerca da parte que cabia a sumérios e semitas na constituição da escrita cuneiforme e da sociedade mesopotâmica; cf nota 11 abaixo.

10 - Nota-se claramente a inspiração peirciana da crítica de Lieberman. Parece-me, no entanto, que o autor restringiu injustificadamente a caracterização sígnica dos tokens, limitando-a à situação de impressão nas superfícies das bullae. Poder-se-ia objetar que a relação sígnica é anterior à impressão, situando-se nos próprios tokens, sendo eles próprios uma representação icônica (ainda que apenas uma minoria do repertório correspondesse à definição). A impressão, neste caso, seria somente um registro gráfico da relação sígnica e, mesmo que implicasse um segundo nível de abstração, na passagem da tridimensionalidade para a bidimensionalidade, não alteraria a natureza da representação.

11 - O debate sobre a existência de uma língua específica registrada pelo proto-cuneiforme e, em caso afirmativo, qual seria, é acirrado e, ao que tudo indica, insolúvel. Os especialistas dividem-se entre os que apóiam a tradicional opção suméria (tradicional, mas relativamente recente, uma vez que a assiriologia enfrentou, ainda nas primeiras décadas deste século, uma intensa discussão sobre a própria existência de uma língua suméria e de uma etnia não semita a que se devesse atribuir a elaboração do sistema cuneiforme (cf. Cooper, 1991), os que vislumbram outros estratos lingüísticos depois desaparecidos (é de se notar o recente alinhamento neste campo de R. Englund, certamente o mais fino conhecedor dos textos arcaicos de Uruk na atualidade (cf. Englund, 1998) e, finalmente, os que insistem em uma desvinculação entre língua e proto-cuneiforme. O chamado "problema sumério" complica ainda mais a questão, especialmente se considerarmos certas incompatiblidades entre os dados arqueológicos (que apontam uma continuidade de ocupação no decorrer do quarto milênio) e os filológicos (por exemplo, a impossibi- 
lidade de explicar a partir da língua suméria o nome de muitas das principais cidades sumérias, deixando entrever a contribuição de uma população não identificada). De todo modo, a questão é considerada secundária pela argumentação de Schmandt-Besserat (Schmandt-Besserat, 1989, p. 57), que entende que o estágio proto-cuneiforme guarda a mesma independência face à fonética que marcara o sistema de tokens, um e outro podendo, assim, ser compartilhado por populações diferentes.

12 - Uma característica que não me parece ser amenizada pelo fato de o sumério ser uma língua aglutinante: bem ao contrário, o ordenamento rígido, que é próprio da disposição dos elementos nas cadeias verbais e nominais e na frase suméria como um todo, conviveria mal com a disposição espacial dos signos nos primeiros tabletes. Talvez aí possamos encontrar um argumento em favor da desvinculação entre grafia e fala nesse estágio. Quanto à disposição dos sinais nas grades típicas dos tabletes proto-cuneiformes, deve-se notar que a sequiência torna-se cada vez mais regulada, numa tentativa de estabelecer uma "ordem de leitura". Isso não significa, todavia, a orientação de uma língua em particular. Apenas sugere que os sinais como também os arranjos são portadores de significado e que, por outro lado, a proliferação desmedida dos tipos de signo foi vista como um problema a ser enfrentado: daí sua drástica redução em fases posteriores.

13 - Poderíamos lembrar as fases arcaizantes tardias, como o neobabilônico no primeiro milênio, em que o uso dos ideogramas acentuou-se consideravelmente. Para uma crítica severa da origem verbal da escrita e uma defesa de seu caráter icônico, com amplo uso do exemplo dos cuneiformes, ver A.-M. Christin (Christin, 1995). A autora aponta que Gelb reconhece o papel da iconicidade nos inícios do grafismo mesopotâmico, mas ressalvando que a verdadeira escrita aparece apenas com a adequação ao fonetismo. Christin percebeu, corretamente, que o postulado equivaleria a uma dupla criação, a primeira icônica, a segunda lingüística (p.12). Esta clivagem é fortemente presente na literatura posterior a Gelb.

14 - Michalowski cita o exemplo de Abada, durante o quinto milênio, em que os tokens aparecem associados às tumbas infantis. Schmandt-Besserat havia pressentido o problema posto pelos tokens encontrados em contextos funerários (como vimos, já presente nas primeiras tentativas de identificação feitas pelos escavadores) e buscou oferecer uma resposta compatível com sua teoria (Schmandt-Besserat, 1988a). A hipótese de os tokens representarem substitutos simbólicos de oferendas aos mortos (alimentos, por exemplo) foi descartada por não fazer parte das práticas culturais do Médio-Oriente, ao contrário do Egito. Outros elementos - a clara limitação das tumbas providas de tokens; sua associação com materiais de prestígio e características arquitetônicas distintas; o uso sensivelmente elevado da pedra para sua confecção, em detrimento da argila - levou a autora a considerá-los como elementos de distinção do status anterior do morto, em particular de membros da elite com acesso privilegiado aos recursos da comunidade. Os tokens funerários, propõe, devem ser vistos como símbolos de prestígio que remetem à atividade de controle contábil e à autoridade a ela associada. Por decorrência, sua presença nas tumbas infantis poderia significar uma relação entre os filhos da elite e o aprendizado das técnicas de controle, como mais tarde ocorrerá entre os escribas e seus instrumentos de trabalho.

15 - Como escavadores do sítio de Warka/Uruk, os alemães tiveram um acesso privilegiado ao principal corpus documental proto-cuneiforme. As escavações do Instituto Arqueológico Alemão iniciaram-se em 1913 e foram interrompidas somente pelas duas Gran- 
des Guerras e, no presente, pela conturbada situação no Golfo Pérsico. Adam Falkenstein publicou o primeiro conjunto significativo de tabletes em 1936. Atualmente, o projeto, sob a coordenação de $\mathrm{H}$. Nissen, dá sequiência à edição completa dos documentos, que se elevam a 5000 tabletes e fragmentos, e à interpretação do sistema de notação. Além dos assiriólogos (Nissen, Englund, Green), a equipe conta com um historiador da ciência, do Instituto Max Plank (P. Damerow) e com o uso massivo de computadores gráficos, o que dá a medida dos problemas de ordem técnica (sobretudo matemática) envolvidos no entendimento do sistema.

16 - À margem do grupo de Berlin, M. Powell (Powell, 1981) seguiu um caminho análogo, aceitando a proposição geral de Schmandt-Besserat, mas insistindo em uma aquisição instantânea da escrita, fruto de um esforço individual, descartando uma evolução gradual geração após geração ou mesmo uma invenção colegiada.

17 - Fora do ambiente mesopotâmico, as teses de Schmandt-Besserat também encontraram resistências: é o caso de Susa, que fora justamente o berço da hipótese de P. Amiet. Para uma visão contrária, ver A. Le Brun e F. Vallat (Le Brun \& Vallat, 1978): mesmo aceitando alguns tópicos específicos da argumentação de Schmandt-Besserat, como por exemplo a possibilidade da existência de uma contabilidade baseada nos tokens e nas bullae, os autores rejeitam o essencial, ou seja, a linha evolutiva até a escrita. Uma apreciação mais favorável encontra-se em C. Herrenschmidt (Herrenschmidt, 1996), que ressalva, no entanto, que a escrita não se desenvolve a partir da representação de elementos concretos, mas da abstração numérica. Vale lembrar que o próprio P. Amiet não procurou desenvolver seu postulado inicial, chegando mesmo a manifestar certas dúvidas quanto à aproximação entre os tokens (segundo ele, um procedimento cuja convencionalidade seria compartilhada pelas pessoas que o utilizavam) e a escrita (esta, sim, um verdadeiro sistema de comunicação) cf. o debate registrado nas p. 30-33 de P. Ferioli, E. Fiandra, G. G. Fissore e M. Frangipane (1994).

18 - Pode-se mesmo falar de uma popularização da tese, como mostram diversas exposições sobre as "origens da escrita" nas duas últimas décadas, em que a presença dos tokens e das bullae mostrou-se incontornável. Ver, por exemplo, os catálogos: B. André-Leicknam e Ch. Ziegler, H. J. Nissen, P. Damerow \& R. K. Englund (1993) e Ch. Bertin e outros (1997).

19 - No mais, um campo que mereceria ser explorado em profundidade, como mostram alguns exemplos ainda mal situados no processo de aquisição da literalidade e de seus desdobramentos: penso, em particular, no caso da chamada ortografia UD.GAL.NUN: trata-se de uma série de exemplos, conhecidos a partir dos textos de Abu Salabikh, Shuruppak e Nippur datados do proto-dinástico, em que os sinais têm um valor diferente do usual (por exemplo, na grafia do nome do deus Enlil: UD pelo determinativo divino dingir, GAL por en, NUN por líl). Os especialistas oscilam entre considerá-la uma forma criptográfica de um estilo ortográfico particular do sumério (Lambert, 1981), uma variação dialetal (o que o faria uma espécie de forma arcaica do emesal, a fala cúltica, talvez inicialmente feminina, dos textos sumérios - cf. Alster, 1982) ou, mais amplamente, um representante dos diversos sistemas comunicativos que conviveram no decorrer do quarto e terceiro milênios a.C. (Michalowski, 1993).

20 - Trata-se apenas de uma referência tipológica ideal: os trabalhos dos pré-historiadores e dos antropólogos têm demonstrado, nas últimas décadas, o quanto as sociedades paleolíticas ou de caçadores-coletores estão longe de uma situação de igualdade genera- 
lizada, conferindo uma visão bem mais nuançada da clássica oposição entre sociedades de classes e sociedades sem classes.

21 - Todos esses casos, evidentemente, podem ser objeto de uma verbalização e do registro escrito. Assim foi nas diversas ocasiões em que as regras de etiqueta passaram a ser objeto de um códice escrito ou em que as técnicas de uso do corpo se tornaram objeto de um discurso médico, por exemplo. Na Mesopotâmia do quarto milênio a.C., no entanto, faziam parte do universo da oralidade.

22 - Tais deduções, porém, não decorrem naturalmente do texto de J.-M. Durand, pelas razões que apontei mais acima.

23 - Não é sem motivo que uma severa crítica à teoria de Schmandt-Besserat estará no centro de seu novo trabalho, ainda inédito, sobre a origem da escrita cuneiforme. Agradeço a cortesia de J.-J.Glassner em adiantar-me os resultados de sua reflexão [nota do autor: o livro (Écrire à Sumer - L'invention du cunéiforme. Paris, Seuil, 2000) aparece agora, após a entrega deste manuscrito para publicação, não me permitido uma consideração detalhada de seu conteúdo].

24 - O argumento não me parece ser enfraquecido pela possibilidade de alguns estágios do sistema de registro estarem associados ao gerenciamento local de pequenas quantidades de bens (como pensou R. Englund - 1998, p. 49). As implicações de uma tal descoberta recairiam mais sobre a caracterização da expansão de Uruk, de suas relações com as áreas coloniais, do que sobre o funcionamento dos sistemas administrativos. SchmandtBesserat já havia posto em dúvida que os tabletes proto-cuneiformes fizessem referência a um comércio de longa distância de materiais custosos, embora aceitasse seu caráter institucional (Schmandt-Besserat, 1981, p. 340); Em todo caso, um estudo quantitativo das informações contidas nos primeiros tabletes (Sweet, 1997) demonstrou que as operações tinham um caráter institucional. No mesmo sentido, parece-me improvável que, em Susa, os registros estivessem associados às atividades privadas de mercadores, como sugeriu P. Amiet, em oposição ao caráter institucional na Mesopotâmia (para uma crítica, ver: Herrenschmidt, 1996, p. 100).

25 - Aí se situa, justamente, a principal fraqueza da teoria de Schmandt-Besserat: ela não prevê nenhuma resposta satisfatória ao processo pelo qual o registro gráfico atrelou-se inexoravelmente à língua. O freqüentemente lembrado estágio do rebus - pelo qual um sinal pictográfico é apropriado pelo seu valor fonético, abstraindo-se a referência inicial ao objeto - certamente exerceu algum papel, mas não pode ser visto, em nenhuma hipótese, como explicação da transição.

26 - Embora me pareçam questionáveis por se mostrarem como uma espécie de avatar das tendências modernizantes em antropologia, não cabe avaliar, aqui, as bases teóricas da análise de Algaze. Note-se apenas que o autor transporta as idéias de I. Wallerstein para uma ambiente bem distinto de seu contexto original, a emergência do capitalismo no quadro da expansão colonial moderna, forçando, assim, as resistências do propositor da teoria. Para Algaze, as reservas de Wallerstein estavam fundadas em uma falsa oposição entre o comércio antigo (baseado em preciosidades) e o comércio dos tempos modernos (envolvendo produtos essenciais, em quantidade massiva), bem como em um contraste equivocado entre os imperialismos antigos (em que as fronteiras da hegemonia política e econômica seriam contíguas) e o expansionismo moderno (em que a dominação econômica extravasaria as fronteiras do controle político). Algaze opõe que o critério essencial é a integração de novas regiões a uma economia em expansão, não importando 
se a forma assumida pela dependência seja prioritariamente econômica ou política. A caracterização do comércio antigo por Wallerstein já havia sido criticada antes por Jane Schneider (Schneider, 1977), justamente em uma reflexão sobre a aplicação do modelo do "world-system" às sociedades pré-capitalistas.

27 - Um desdobramento importante, já sugerido por Goody, foi a superioridade dos sistemas alfabéticos face aos silábicos (no caso do cuneiforme, seria mais exato falar de fonêmico) quanto à capacidade de geração de formas sociais e de pensamento. O trabalho clássico de Eric Havelock (Havelock, 1982) se ressente enormemente dessa perspectiva, situando na adoção do alfabeto pelos gregos o motor crucial de seu desenvolvimento intelectual particular. Uma filiação ao logocentrismo contemporâneo, sem dúvida, mas também, no limite, passível de ser enquadrada no antisemitismo que perpassa, segundo o polêmico Martin Bernal, os estudos clássicos (cf. Daniels, 1996, p. 27 ss.). Mais recentemente, Marcel Detienne (Detienne, 1992) retornou ao problema: negando que um sistema gráfico qualquer seja portador da racionalidade, salientou, no entanto, que a escrita não pode ser vista como um sub-produto da oralidade, como simples reprodução de um discurso pré-existente. Assim, não sendo apenas uma tecnologia de registro, mas uma verdadeira prática social, a escrita se afirma como uma forma de pensar, uma operação cognitiva com autonomia suficiente para produzir seus próprios objetos e força bastante para abrir ao intelecto perspectivas impensáveis em uma situação de ausência do grafismo. Estamos longe, no entanto, de uma defesa das potencialidades criadoras do alfabeto ou mesmo de uma superioridade face a outros sistemas gráficos. Das considerações de Detienne, parece poder-se deduzir que as diferenças entre os sistemas de pensamento ocidental (grego) e médiooriental devem ser explicadas a partir de um contexto mais amplo. Por isso mesmo não deixa de ser surpreendente que muitos assiriólogos aceitem passivamente uma hierarquia tão questionada alhures. Se é compreensível que, no início do século, G. Contenau (Contenau, 1927, p. 194 ss.) estabelecesse uma linha evolutiva do sistema pictográfico ao alfabético, em que o silábico serviria de elo de transição, ou, ainda, que atribuísse a inferioridade do sistema mesopotâmico ao fato de que a aquisição de características novas (fonêmicas) não levara ao abandono das antigas (pictográficas, ideográficas), é, por outro lado, difícil concordar com Durand (Durand, 1977, p. 28), ao afirmar que a resistência do sistema cuneiforme em desaparecer face a outro mais evoluído tenha paralisado a evolução intelectual de uma parte do mundo antigo. Por outro lado, do ponto de vista estritamente técnico, as supostas dificuldades impostas pelo cuneiforme ao aprendizado e à reprodução do sistema têm suscitado reservas de vários especialistas (cf. Diakonoff, 1975, p. 101 ss., Powell, 1981, p. 434 ss. e Vanstphout, 1995, p. 2188).

28 - O conceito já havia sido proposto por Kathleen Gough em 1968, interessantemente numa coletânea organizada pelo próprio Goody.

29 - Vejam-se, no entanto, os excelentes trabalhos reunidos por M. E. Vogelzang e H. L. J. Vanstiphout, em 1992.

30 - Embora ainda seja fortemente presente uma tendência, inaugurada pela obra clássica de $\mathrm{H}$. Frankfort, a considerar as impressões do ponto de vista da arte e focalizando seus aspectos decorativos e as ligações com o universo imaginário (de resto, um campo de estudo em que há muito por fazer, como mostram as limitações dos trabalhos de E. Porada, P. Amiet e, mais recentemente, D. Collon), a literatura especializada tem enfatizado as práticas de controle administrativo envolvidas no uso dos selos cilíndricos (cf. sobretudo Pittmann, 1994a e 1994b; e também Rova, 1994; para Susa, ver Dittmann, 1986). 


\section{Referências bibliográficas}

ADAMS, R. McC. Heartland of cities: surveys of ancient settlement and land use on the central floodplain of the Euphrates. Chicago: University of Chicago Press, 1981.

ADAMS, R. McC. \& NISSEN, H. The Uruk countryside: the natural setting of urban societies. Chicago: University of Chicago Press, 1972.

ALGAZE, G. The Uruk world system. The dynamics of expansion of Early Mesopotamian civilization. Chicago: The University of Chicago Press, 1983.

ALSTER, B. Emesal in Early Dynastic Sumerian? What is the UD.GAL.NUN-ortography? In: Acta Sumerologica Japanesa, 4, 1982 (1-6).

AMIET, P. Il y a 5000 ans les Elamites inventaient l'écriture. In: Archéologia, 12, p. 17-23, 1966.

. "Sceaux et administration à l'époque d'Uruk, à Suse" In: FERIOLI, P.; FIANDRA, E; FISSORE, G. G. \& FRANGIPANE, M. (Eds.). Archives before writing. Roma: Publicazione Degli Archivi di Stato, 1994.

ANDRE-LEICKNAM, B. \& ZIEGLER, Ch. (Eds.). Naissance de l'écriture. Cunéiformes et hiéroglyphes. Paris: Éditions de la Réunion des Musées Nationaux, 1982.

BERTIN, Ch. et alii. En Syrie aux origines de l'écriture. Tunhout: Brepols, 1997.

BOTTERO, J. “De l'aide-mémoire à l'écriture”. In: Mésopotamie. L'écriture, la raison et les dieux. Paris: Gallimard, 1987.

BRANDES, M. A. Modelage et imprimerie aux débuts de l'écriture en Mésopotamie. In: Akkadica, 18, p. 1-30, 1980.

BRETON, L. Le. The early periods at Susa, Mesopotamian relations. In: Iraq, 19, p. 79124, 1957.

BRUN, A. Le \& Vallat, F. L'origine de l'écriture à Suse. In: Cahier de la Délégation Archéologique Française en Iran, 8, p. 11-57, 1978.

CHRISTIN, A. M. L'image écrite ou la déraison graphique. Paris: Flammarion, 1995.

CONTENAU, G. Manuel d'Archéologie Orientale. Paris: Éditions Auguste Picard, 1927, vol. I.

COOPER, J. S. Posing the sumerian question: race and scholarship in the early history of Assiriology. In: Aula Orientalis, 9, p. 47-66, 1991.

DAMEROW, P \& ENGLUND, R. K. "Die Zahlzeichensysteme der Archaischen Texte aus Uruk”. In: GREEN, M. W. \& NISSEN, H.J. (Eds.). Zeichenliste der Archaischen Texte aus Uruk. Berlin: Gebr. Mann Verlag, 1987.

DANIELS, P. T. "The study of writing systems”. In: DANIELS, P. T. \& BRIGHT, W. (Eds.). The world's writing systems. Oxford: Oxford University Press, 1996.

DETIENNE, M. “L'écriture et ses nouveaux objets intellectuels en Grèce”. In: Les savoirs de l'écriture en Grèce Ancienne. Lille: Presses Universitaires de Lille, 1992.

DIAKONOFF, I. M. Ancient writing and ancient written language: pitfalls and peculiarities in the study of Sumerian. In: LIEBERMAN, S. J. (Ed.). Sumerological studies in honor of Thorkild Jacobsen. Chicago: University of Chicago Press, 1975. 
DITTMANN, R. Seals, sealing and tablets. Thoughts on the changing pattern of administrative control from the late-Uruk to the proto-Elamite period at Susa. In: FINKBEINER, U. \& RÖLLIG, W. (Eds.). Gamdat Nasr Period or Regional Style? Wiesbaden: Ludwig Reichert Verlag, 1986.

DURAND, J-M. Diffusion et pratiques des écritures cunéiformes au Proche-Orient ancien. L'espace et la lettre, Cahiers Jussieu. 3. Paris: Union Générale d'Éditions, 1977.

ENGLUND, R. The origins of script. In: Science, 260, p. 1670-1671, 1993.

. "Texts from the late Uruk period”. In: BAUER, J., ENGLUND, R. K. \& KREBERNIK, M. Mesopotamien Späturuk-Zeit und Frühdynastische Zeit. Freiburg/ Göttingen: Universitätsverlag/ Vandenhoeck \& Ruprecht, 1998.

FALKENSTEIN, A. Archaische texte aus Uruk. Berlin: Deutshe Forschungsgemeinschaft, 1936.

FERIOLI, P., FIANDRA, E., FISSORE, G. G. \& FRANGIPANE, M. (Eds.). Archives before writing. Roma: Publicazione Degli Archivi di Stato, 1994.

GELB, I. J. A study of writing. The foundations of grammatology. Chicago: Chicago University Press, 1952.

GLASSNER, J.-J, L'Écriture sumérienne: invention et prémiers usages. Revue Européenne des Sciences Sociales, 26, p. 33-45, 1998.

Écrire à Sumer - l'invention du cunéiforme. Paris: Seuil, 2000.

GOODY, J. 1986. The logic of writing and the organization of society. Cambridge: Cambridge University Press, 1986.

GOODY, J. \& WATT, I. The consequences of literacy. Coparative Studies in Society and History, 5, p. 304-345, 1963.

GREEN, M. W. The construction and implementation of cuneiform writing system. Visible Language, 15, p. 345-372, 1981.

GUNDER-FRANK, A. Bronze Age world systems cycles. Current Anthropology, 34, p. 383-429, 1993.

HAVELOCK, E. The literate revolution in Greece and its cultural consequences. Princeton: Princeton University Press, 1982.

HERRENSCHMIDT, C. "La civilisation élamite et l'écriture”. In: BOTTERO, J., HERRENSCHMIDT, C. \&.VERNANT, J.-P. L'Orient Ancien et nous. L'écriture, la raison, les dieux. Paris: Albin Michel, 1996.

JORDAN, J - Zweiter vorläufiger Bericht über die von der Notgemeinschaft der Deutschen Wissenchaft in Uruk Unternommenen Ausgrabungen (=UVB,2). Berlin: Verlag der Akademie der Wissenschaften, 1931.

LAMBERT, W. G. Studies in UD.GAL.NUN. Oriens Antiquus, 20, p. 81-97, 1981.

LARSEN, M. T. “Introduction: Literacy and Social Complexity”. In: GLEDHILL, J., BENDER, B. \& LARSEN, M. T. (Ed.). State and society. The emergence and development of social hierarchy and political centralization. London: Unwin Hyman, 1988. 
LENZEN, H. J. XXI vorläufiger Bericht über die dem Deutschen Archäologischen Istitut und der Deutschen Orient-Gesellschaft aus Mitteln der Deutschen Forchungsgemeinschaft unternommenen Ausgrabungen in Uruk-Warka $(=U V B, 21)$. Berlin: Verlag Gebr. Mann, 1965.

LIEBERMAN, S. J. Of clay pebbles, hollow clay balls, and writing: a sumerian view. American Journal of Archaeology, 84, p. 339-358, 1980.

LIVERANI, M. "Final remarks". In: FERIOLI, P., FIANDRA, E., FISSORE, G. G. \& FRANGIPANE, M. (Eds.). Archives before writing. Roma: Publicazione Degli Archivi di Stato, 1994.

MATTHEWS, R. L'émergence de l'écriture au Proche-Orient". In: BERTIN, Ch. et alii. En Syrie aux origines de l'écriture. Turnhout: Brepols, 1997.

MECQUENEM, R. “Les fouilles de Suse - 1929-1933”. In: Mémoires de la Mission Archéologique de Perse. Mission en Susiane, 25, p. 177-237, 1934.

."Fouilles de Suse - 1933-1939". In: Mémoires de la Mission Archéologique en Iran. Mission de Susiane, 29, 1943 (3-161).

MICHALOWSKI, P. "Early Mesopotamian communicative systems: art, literature, and writing”. In: GUNTER, A. C. (Ed.). Investigating artistic environments in the ancient Near East. Washington: 1990.

."On the early toponomy of Sumer: a contribuition to the study of early Mesopotamian writing” In: RAINEY, A. F. (Ed.). Kinattûtu sha dârâti. Raphael Kutscher Memorial Volume. Tel Aviv: Institut of Archeology, 1993.

. "Mesopotamian cuneiform" In: DANIELS, P. T. \& BRIGHT, W. (Eds.) - The world's writing systems. Oxford: Oxford University Press, 1996.

MILANO, L. "Origine, difussione e sviluppo della scrittura cuneiforme”. In: MATTHIAE, P. PINNOCK, F. \& MATTHIAE, G. S. (Eds.). Ebla - alle origini della civiltà urbana. Milano: Electa, 1995.

NISSEN, H. J. "L'invention de l'écriture cunéiforme: les tablettes archaïques d'Uruk". In: BERTIN, Ch. et alii. En Syrie aux origines de l'écriture. Turnhout: Brepols, 1997.

NISSEN, H. J., DAMEROW, P. \& ENGLUND, R. K. Archaic Bookkeping. Writing and techniques of economic administration in the ancient Near East. Chicago: Chicago University Press, 1993.

OPPENHEIM, A. L. On an operational device in Mesopotamian burocracy. In: Journal of Near Eastern Studies, 18, p. 121-128, 1959.

PALLIS, S. A. The antiquity of Iraq. A handbook of assyriology. Copenhagen: Ejnar Munksgaard, 1956.

PITTMANN, H. The glazed steatite glypitic style - The structure and function of an image system in the administration of protolitarate Mesopotamia (=BBVO,16). Berlin: Dietrich Reimer Verlag, 1994a.

."Towards an understanding of the glyptic imagery in the administrative systems of proto-literate greater Mesopotamia”. In: FERIOLI, P., FIANDRA, E., FISSORE, G. G. \& FRANGIPANE, M. (Eds.). Archives Before Writing. Roma: Publicazione Degli Archivi di Stato, 1994b. 
POURSAT, J.-Cl. "Les systèmes primitifs de comptabilité en Crète minoenne". In: FERIOLI, P., FIANDRA, E., FISSORE, G. G. \& FRANGIPANE, M. (Eds.). Archives Before Writing. Roma: Publicazione Degli Archivi di Stato, 1994b.

POWELL, M. A. Three problems in the history of cuneiform writing: origins, direction of script, literacy. Visible Language, 15, p. 419-440, 1981.

ROVA, E. Ricerche sui sigilli a cilindro vicino-orientali del periodo di Uruk/Jemdet Nasr. Roma: Instituto per l'Oriente C. A. Nallino, 1994.

SCHMANDT-BESSERAT, D. An archaic recording system and the origin of writing. SyroMesopotamian studies, 1, p. 31-70, 1977.

.The earliest precursor of writing. Scientific American, 238, p. 38-47, 1978a.

. "An early recording system in Egypt and the ancient Near East". In: SCHMANDTBESSERAT, D. (Ed.). Immortal Egypt, Malibu: Undena Publications, 1978b.

. From tokens to tablets: a re-evaluation of the so-called 'numerical tablets'. Visible Language, 15, p. 321-343, 1981.

. Tokens at Susa. Oriens Antiquus, 25, p. 93-125, 1986.

Tokens as funerary offerings. Vicino Oriente, 7, p. 3-9, 1988a.

. Tokens at Uruk. Baghdader Mitteilungen, 19, p. 1-175, 1988b.

. "Conto e contabilità nel medio oriente preistorico". In: FALES, F. M. (Ed.). Prima dell'alfabeto - La storia della scrittura attraverso testi cuneiformi inediti. Venezia: Erizzo Editrice, 1989.

. Before writing, vol. 1: From counting to cuneiform. Austin: University of Texas Press, 1992.

"Tokens: a prehistoric archive system". In: FERIOLI, P., FIANDRA, E., FISSORE, G. G. \& FRANGIPANE, M. (Eds.). Archives before writing. Roma: Publicazione Degli Archivi di Stato, 1994.

"Record keeping before writing". In: SASSON, J. (Ed.). Civilizations of the ancient Near East, vol. IV. New York: Charles Scribner's Sons, 1995.

SCHNEIDER, J. Was there a pre-capitalist world system? Peasant Studies, 6, p. 20-29, 1977.

SHENDGE, M. J The use of seals and the invention of writing. Journal of the Social and Economic History of the Orient, 26, p. 113-136, 1983.

The inscribed calculi and the invention of writing: the Indus view. Journal of the Social and Economic History of the Orient, 28, p. 50-80, 1985.

SWEET, R. F. G. "Writing as a factor in the rise of urbanism". In: AUFRECHT, W. E, MIRAU, N. A. \& GAULEY, S. W. (Eds.). Urbanism in Antiquity from Mesopotamia to Crete, Journal for the Study of the Old Testament, Supplement Series, 244, 1997.

VANSTIPHOUT, H. L. J. "Memory and literacy in ancient western Asia". In: J. SASSON (Ed.). Civilizations of the Ancient Near East, vol. IV. New York: Charles Scribner's Sons, 1995. 
VOGELZANG, M. E. \& VANSTIPHOUT, H. L. J. (Eds.). Mesopotamia epic literature, oral or aural? Lewiston: Edwin Mellen Press, 1992.

WRIGHT, H. T. \& JOHNSON, G. A. Population, exchange, and early satate formation in southwestern Iran. American Anthropologist, 77, p. 267-289, 1975.

ZAGARELL, A. Trade, women, class, and society in ancient Western Asia. Current Anthropology, 27, p. 415-430, 1986.

REDE, Marcelo. Complexité sociale, systèmes de communication et génèse de l'écriture cunéiforme. Classica, São Paulo, 11/12, p. 37-59, 1998/1999.

RESUMÉ: Cette étude vise à exposer et discuter les théories les plus récentes sur l'origine de l'écriture en Mésopotamie. Notre examen se portera plus particulièrement sur les diverses propositions concernant l'articulation entre la genèse de l'écriture cunéiforme, la diversité et les fonctions des systèmes de communication et un contexte social de plus en plus complexe à la fin de la période néolithique.

MOTS-CLÉS: cunéiforme; écriture; Mésopotamie; systèmes de communication; complexité sociale. 